\title{
TÉCNICA DE BORDADO EN LÍNEA PARA EL DESARROLLO CREATIVO Y MOTOR APLICABLE EN LAS CLASES DE EDUCACIÓN ARTÍSTICA DE LA ESCUELA SECUNDARIA
}

\section{ARTÍCULO ORIGINAL}

DUTRA, Ana Paula de Souza ${ }^{1}$, FECURY, Amanda Alves², DENDASCK, Carla Viana ${ }^{3}$, OLIVEIRA, Euzébio de ${ }^{4}$, DIAS, Claudio Alberto Gellis de Mattos ${ }^{5}$

DUTRA, Ana Paula de Souza. Et al. Técnica de bordado en línea para el desarrollo creativo y motor aplicable en las clases de educación artística de la escuela secundaria. Revista Científica Multidisciplinar Núcleo do Conhecimento. Año 06, Ed. 01, Vol. 08, págs. 26-33. Enero de 2021. ISSN: 2448-0959, Enlace de acceso: https://www.nucleodoconhecimento.com.br/educacion-es/bordado-en-linea, DOI: 10.32749/nucleodoconhecimento.com.br/educacion-es/bordado-en-linea

\section{RESUMEN}

La educación artística se compone de varias técnicas que conducen al desarrollo del pensamiento lógico, la creatividad y la coordinación motora. El objetivo de este trabajo es describir una técnica de bordado en línea para el desarrollo creativo y motor aplicable en las clases de educación artística de la escuela secundaria. El método descrito será el bordado libre - imágenes, una técnica que utiliza tela, aguja

\footnotetext{
${ }^{1}$ Licenciado en Bellas Artes (FAAP SP), estudiando Especialización en Artes, Rudolf Steiner College (FRS SP).

${ }^{2}$ Biomédica, Doctora en Enfermedades trópicas, Profesora e investigadora del Curso Médico del Campus macapá de la Universidad Federal de Amapá (UNIFAP).

${ }^{3}$ Teóloga, Doctora en Psicoanálisis Clínica. Ha trabajado durante 15 años con Metodología Científica (Método de Investigación) en la Orientación de Producción Científica de estudiantes de Maestría y Doctorado. Especialista en Investigación e Investigación de Mercados con foco en el área de la Salud. ${ }^{4}$ Biólogo, Doctor en Enfermedades trópicas, Profesor e investigador del Curso de Educación Física de la Universidad Federal de Pará (UFPA).

${ }^{5}$ Biólogo, Doctor en Teoría e Investigación del Comportamiento, Profesor e investigador del Curso de Grado en Química del Instituto de Educación Básica, Técnica y Tecnológica de Amapá (IFAP) y del Programa de Posgrado en Educación Profesional y Tecnológica (PROFEPT IFAP).
}

RC: 73421

Disponível em: https://www.nucleodoconhecimento.com.br/educacion-es/bordado- 
e hilos, así como imágenes. El uso de la técnica de bordado libre - Las imágenes descritas pueden ser capaces de proporcionar a los estudiantes de secundaria un mayor desarrollo en las capacidades de concentración (enfoque, atención), motricidad y creatividad. La técnica de respetar al individuo en su individualidad de aprendizaje y ludicidad también parece influir en el aumento de estas capacidades. La técnica descrita se puede adaptar silenciosamente a diferentes regiones, como sucede en Brasil, un país de dimensiones continentales y diversidad sin precedentes.

Palabras clave: Bordado Libre, Motricidad, Concentración, Creatividad.

\section{INTRODUCCIÓN}

Dentro del currículo educativo brasileño hay un componente llamado educación artística (BRASIL, 1997). La educación artística se compone de varias técnicas que conducen al desarrollo del pensamiento lógico, la creatividad y la coordinación motora, utilizando la expresión del sentimiento (EÇA, 2010). Entre estas técnicas se encuentran las obras manuales, llamadas así porque se llevan a cabo con sus manos (RAMOS, 2013), como pintura, bordado, ganchillo, macramá y artesanías (GUEDES et al., 2011).

Es posible producir diferentes tipos de trabajo manual (GUEDES et al., 2011). Crafts es un grupo de trabajos manuales realizados con diferentes componentes creando las más variadas formas (pintura, bordado, ganchillo, macramá, cestería, cerámica) (RAMOS, 2013). En la pintura, se suelen utilizar pinturas u otros modos de impresión, y un sustrato (papel, madera, lienzo, etc.) para hacer la representación gráfica de una imagen (CASTILHO et al., 2017). En el bordado se utiliza un tejido como base donde el conjunto de diferentes agujas e hilos realizan acabados con formas geométricas o figuras (RAMOS, 2013).

$\mathrm{RC}: 73421$

Disponível em: https://www.nucleodoconhecimento.com.br/educacion-es/bordadoen-linea 
En las escuelas primarias y secundarias parece ser más que apropiado la enseñanza del trabajo manual. Trabajo artesanal interdisciplinariedad, un concepto importante para la adquisición global de conocimiento. También estimula la creatividad y la resolución de problemas. Esto se traduce en un ciudadano humanizado que entiende mejor al otro y al mundo (TEIXEIRA, 2020).

Hay diferentes tipos de trabajo manual que se pueden utilizar en la enseñanza. Entre ellos, el bordado de punto de cruz, el ganchillo y el tejido de punto son el trabajo a mano que utilizan líneas de varios tipos trenzados con diferentes agujas y se enseñan desde la infancia en varias regiones de Brasil (ALMEIDA, 2003; SANTOS et al., 2012). El macram utiliza diferentes tipos de hilos trenzados (sisal, cadena) para diferentes formas objetos (soportes de jarrones, cortinas, adornos) (VERMA et al., 2019).

Para desarrollar estos trabajos existen varias técnicas de bordado diferentes. Entre ellos la técnica del bordado libre donde cada persona bordea según su creatividad, sin parámetros preestablecidos (MENDONÇA y AGUIAR, 2015).

El trabajo manual, como el bordado, por ejemplo, estimula la capacidad motora de los niños haciéndoles utilizar la musculatura en movimientos llamados finos. La concentración también se amplifica en los estudiantes con esta práctica escolar. (TEIXEIRA, 2018).

El trabajo en línea estimula y aumenta la creatividad en los estudiantes. La expresión personal donde se entrelaza la reproducción de imágenes y la creación estimula tanto el conocimiento como la propia creación (BERGAMO y SILVA, 2020)

\section{GOL}

Describa una técnica de bordado en línea para el desarrollo creativo y el motor aplicable en las clases de educación artística de la escuela secundaria.

$\mathrm{RC}: 73421$

Disponível em: https://www.nucleodoconhecimento.com.br/educacion-es/bordadoen-linea 


\section{MATERIAL Y MÉTODO}

\section{MATERIALES}

- Tejido de algodón 50 cm x 50 centímetros, uno por estudiante;

- Estante de madera de 30 centímetros, uno por estudiante;

- Líneas de colores variados, 08 metros por estudiante;

- Líneas de madejas de colores variados, 08 metros por estudiante;

- Agujas para los números de bordado 22 y 24 para punto de cruz, un par para cada estudiante;

- Recortar tijeras, una para cada estudiante;

- Seleccione dos imágenes (variadas) por estudiante e imprímalas en blanco y negro en tamaño 14 centímetros por 10 centímetros (1/4 de papel A4).

\section{MÉTODO}

Técnica de bordado libre - Imágenes

Esta técnica se aplica y termina en cuatro clases de 50 minutos cada una. Las clases deben tener un número máximo de 10 estudiantes.

Los materiales enumerados deben estar dispuestos delante de cada alumno al comienzo de la lección. Las imágenes impresas deben colocarse en pares aleatorios junto con el resto de los materiales. Tanto las imágenes como las líneas se pueden intercambiar entre los estudiantes. Las imágenes sólo al principio de la aplicación de la técnica, y las líneas en cualquier momento durante las clases.

RC: 73421

Disponível em: https://www.nucleodoconhecimento.com.br/educacion-es/bordadoen-linea 
Paso 1: La imagen en la que se va a trabajar debe ser elegida por cada estudiante, entre las imágenes disponibles.

Paso 2: Cada tejido de algodón $(50 \times 50 \mathrm{~cm})$ debe colocarse en el estante de madera $(30 \mathrm{~cm})$, dejándolo lo más estirado posible (Figura 1).

Figura 1 Muestra el bastidor (A), el tejido de algodón (B) y la tela dentro del bastidor (C).
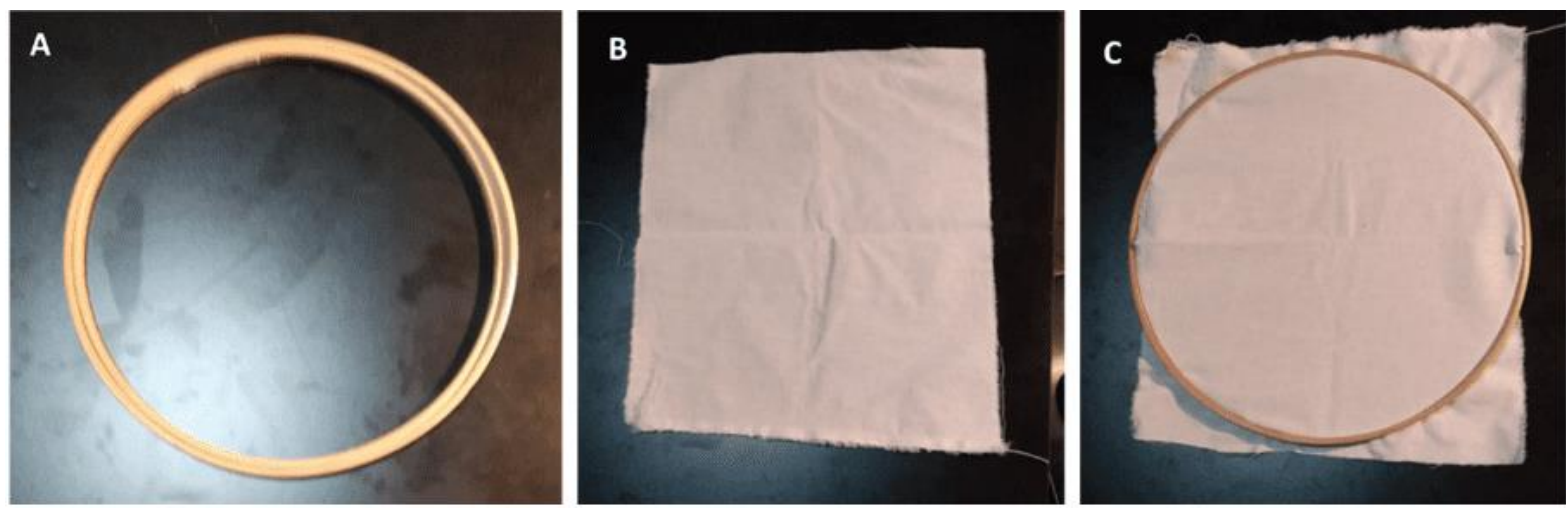

Paso 3: Los estudiantes deben seleccionar los colores y tipos de línea (que pueden ser ambos tipos) para usar. Estas líneas se pueden socializar durante el proceso (Figura 2).

$\mathrm{RC}: 73421$

Disponível em: https://www.nucleodoconhecimento.com.br/educacion-es/bordadoen-linea 
Figura 2 Muestra ejemplos de hilos de algodón que se pueden utilizar.

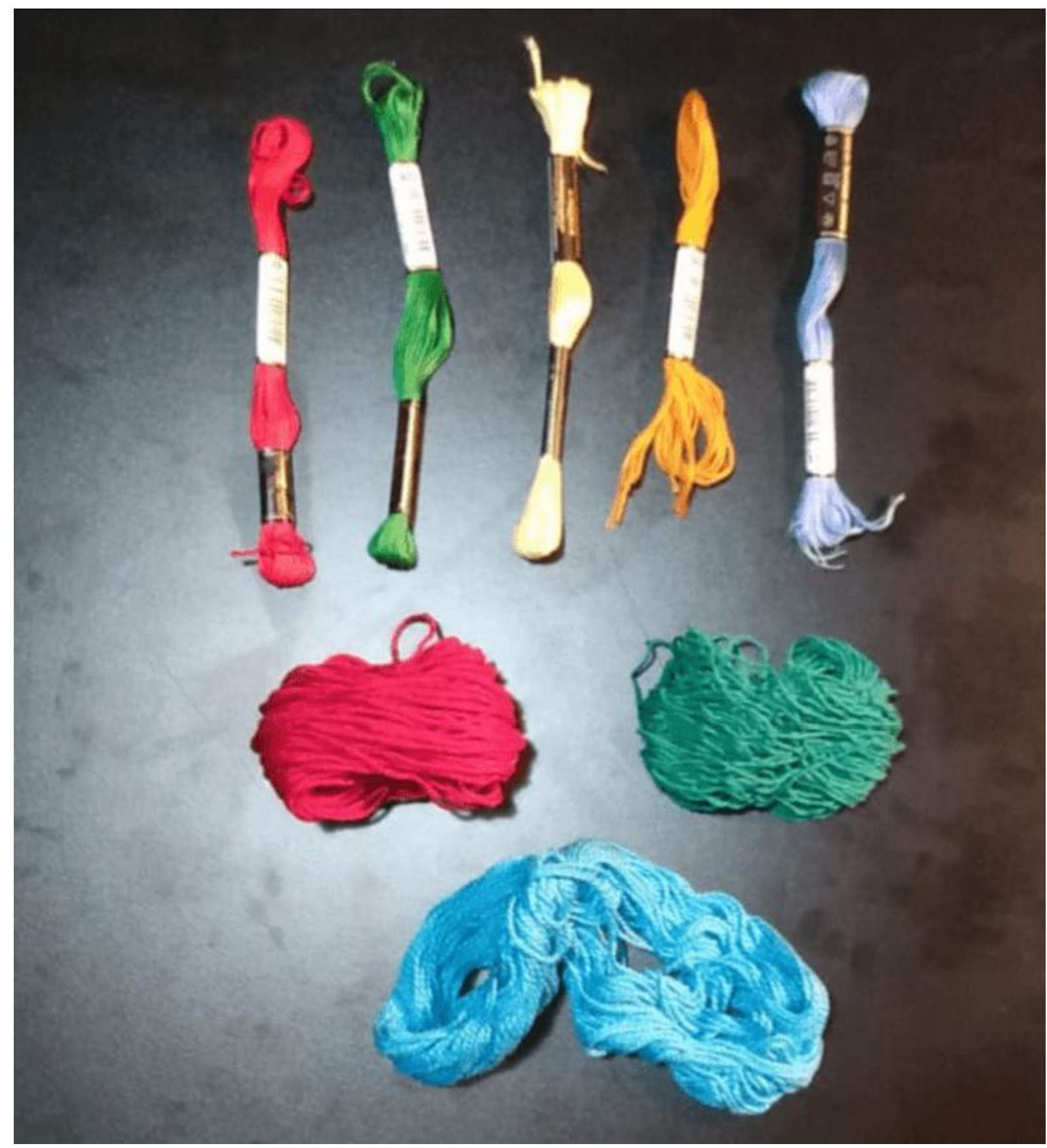

Paso 4: Cada estudiante corta $40 \mathrm{~cm}$ piezas de las líneas (tipo y color) elegidas para realizar el trabajo. Las líneas se pueden cambiar o no durante el proceso.

RC: 73421

Disponível em: https://www.nucleodoconhecimento.com.br/educacion-es/bordadoen-linea 
Paso 5: Cada estudiante elige entre agujas de bordado disponibles (22 ○ 24) y coloca la primera de las líneas en esto (Figura 3).

Figura 3 Muestra los números cedgeneedles 22 (A) y 24 (B)

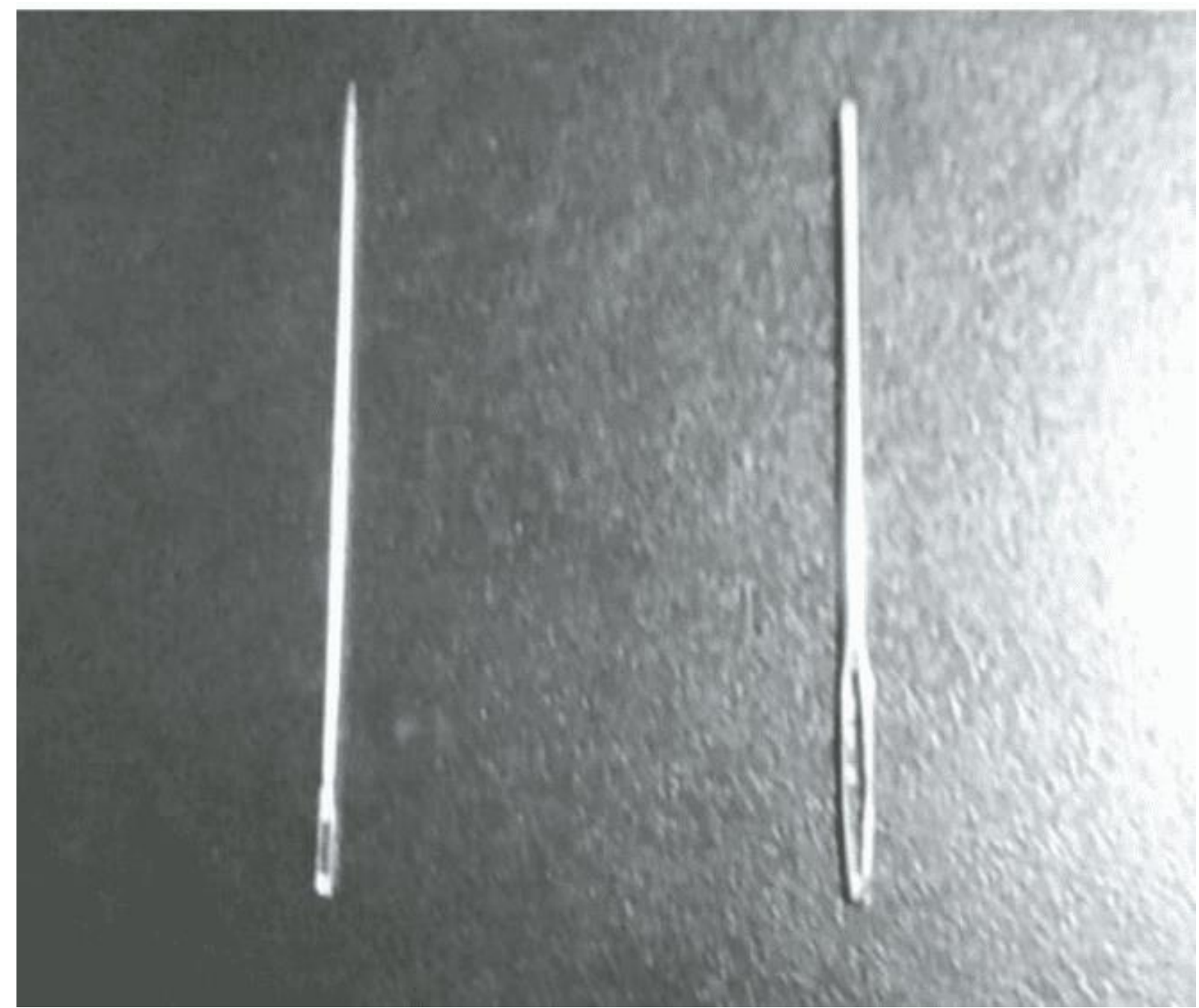

Paso 6: El maestro ejemplifica en una tela, colocada en un backstage, el punto llamado "Behind". Este punto se hará en gran tamaño y con línea roja para una mejor visualización. El maestro enseñará a los alumnos los posibles tamaños de este tipo de punto (Figura 4).

RC: 73421

Disponível em: https://www.nucleodoconhecimento.com.br/educacion-es/bordado- 
Figura 4 Muestra los pasos para hacer la puntada "Atrás", con hilo de tela de algodón unido a estante de madera.
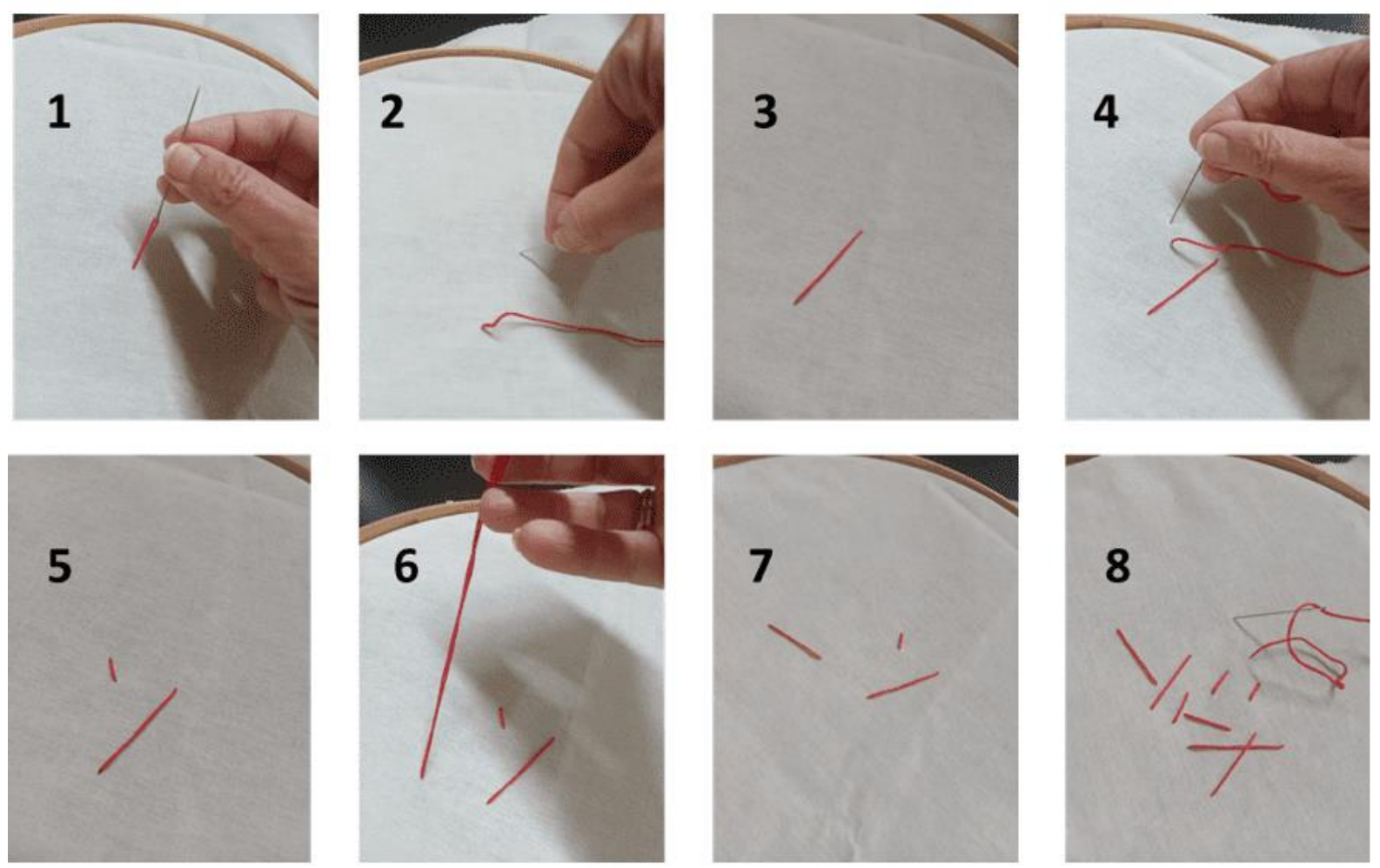

Paso 7: Cada estudiante debe colocar delante de ellos la imagen que han elegido previamente.

Paso 8: A partir de la observación de la imagen cada estudiante debe tratar de reproducir la imagen o una interpretación libre de la misma en la tela, utilizando el tipo de punto 'Detrás'. También debe elegir los diferentes tamaños de punto, utilizando un solo tamaño o alterándolos.

\section{RESULTADOS EXPECTADOS}

Se espera que, al final del período, cada alumno termine su representación con hilo en la tela. Los estudiantes también deben presentar la evolución en su capacidad para observar (concentración, enfoque) motor y creativo.

RC: 73421

Disponível em: https://www.nucleodoconhecimento.com.br/educacion-es/bordadoen-linea 


\section{DISCUSÍON}

El acto de enseñanza y aprendizaje se ha convertido en un camino racional y mecánico, conceptual, renunciando a lo subjetivo, lúdico y estético. En los estudiantes adolescentes modernos, los factores psicoemocionales parecen influir en la formación de pensamientos y, por lo tanto, en el aprendizaje. La pedagogía Waldorf aboga entonces por el enriquecimiento del aprendizaje (concentración) a través de actividades y experiencias artísticas. Los contenidos de las disciplinas están vinculados a una práctica (actividades artesanales, por ejemplo) y a una actividad artística (Ilamada vehículo didáctico) (SILVA, 2015).

En una escuela con la filosofía Waldorf, usted enseña a los estudiantes el trabajo manual. Los adolescentes de décimo año, de acuerdo con el plan de estudios de la escuela, son capaces de diseñar objetos hechos a mano utilizando técnicas de tapicería. Esto requiere las habilidades motoras del estudiante y una alta concentración (LUZ, 2016).

Hay estudiantes que tienen un síndrome que reúne el déficit de atención, el déficit motor y el déficit de percepción, llamado síndrome de MPD. Las investigaciones muestran que las personas con dificultades en las áreas de atención (concentración, enfoque), motricidad (gruesa y fina) y el lenguaje, cuando se exponen a la enseñanza que privilegio la expresión de la libertad y los componentes artísticos, incluyendo las obras manuales, tienden a presentar mejoras en sus pinturas. Se potencia la concentración (atención), la motricidad y la interacción social (SOUSA, 2011).

Un estudio de caso de un solo sujeto realizado durante un período de dos años demostró que el ser humano desarrolla una coordinación de persona a mano, indispensable para la escritura. Este tipo de coordinación es la misma que se adquiere y se automatiza a la hora de aprender y dominar las técnicas de trabajo

$\mathrm{RC}: 73421$

Disponível em: https://www.nucleodoconhecimento.com.br/educacion-es/bordadoen-linea 
manual con línea, por ejemplo. Para el aprendizaje y dominio de esta motricidad es necesario practicar, como se hace en clases de artes (PATERNOST, 2000).

Los estudiantes con dificultades para escribir (disgrafía) generalmente tienen inteligencia normal o superior a la estándar. La dificultad que presentan dificulta, sin embargo, su rendimiento escolar. El proceso de uso del trabajo manual con este estudiante (tejido, ganchillo y tejido), asociado con la diversidad de espacios y la libertad de imaginación (método Waldorf), permite experiencias físicas que ayudan en la mejora de esta imagen (FONSECA et al., 2020).

Un informe portugués sobre la enseñanza supervisada, realizado con clases de educación primaria y secundaria, demuestra que los estudiantes pueden desarrollar su creatividad a través de varias técnicas diferentes, incluyendo el trabajo manual. Entre los tipos de trabajo aparecen las obras con líneas (ganchillo y tejer) (GOUVEIA, 2012).

Los adolescentes con mayor tiempo de exposición a la vida virtual tienen algunas deficiencias en comparación con los adolescentes que tienen un tiempo de exposición más corto. La actividad motora es menor en las personas que están estrechamente vinculadas a las actividades con la pantalla que aquellos que practican actividades físicas (deportes). El tiempo dedicado a los juegos virtuales, por ejemplo, puede causar una caída de la concentración vinculada al pensamiento tranquilo y la contemplación. Las actividades virtuales también parecen proporcionar una caída en la creatividad, en detrimento de quienes utilizan actividades manuales (SETZER, 2014).

\section{CONCLUSIÓN}

El uso de la técnica de bordado libre - Las imágenes descritas pueden ser capaces de proporcionar a los estudiantes de secundaria un mayor desarrollo en las capacidades de concentración (enfoque, atención), motricidad y creatividad.

RC: 73421

Disponível em: https://www.nucleodoconhecimento.com.br/educacion-es/bordadoen-linea 
La técnica de respetar al individuo en su individualidad de aprendizaje y ludicidad también parece influir en el aumento de estas capacidades.

La técnica descrita se puede adaptar silenciosamente a diferentes regiones, como sucede en Brasil, un país de dimensiones continentales y diversidad sin precedentes.

\section{REFERENCIAS}

ALMEIDA, R. N. M. D. Plano de negócios de uma loja de artigos para tircô, crochê e bordado ponto cruz. 2003. 123p. (Graduação). Universidade Federal de Santa Catarina, Florianópolis SC.

BERGAMO, M. L.; SILVA, A. L. Doilies Digitais: Um Estudo da Aplicação de Criatividade Computacional ao Crochê. DATJournal, v. 5, n. 1, p. 138-152, 2020.

BRASIL. Parâmetros curriculares nacionais: arte / Secretaria de Educação Fundamental. SEF. Brasília DF: MEC/SEF: 130p. p. 1997.

CASTILHO, M. A. et al. Artesanato e saberes locais no contexto do desenvolvimento local. Interações (Campo Grande), v. 18, n. 3, 2017.

EÇA, T. T. A Educação Artística e as Prioridades Educativas do Início do Século XXI. Revista Iberoamericana de Educación, n. 52, p. 127-146, 2010.

FONSECA, S. M. D. F. P. D. et al. Coordenação motora fina: do Direito às propostas pedagógicas da Pedagogia Waldorf em disgráficos. Braz. J. of Develop., v. 6, n. 9, p. 71688-71705, 2020.

GOUVEIA, L. R. D. R. Relatório da Prática de Ensino Supervisionada em Ensino de Artes Visuais no 3ํㅡㄹ Ciclo do Ensino Básico e Secundário. Universidade de Évora. Evora PT, p.1-112. 2012

RC: 73421

Disponível em: https://www.nucleodoconhecimento.com.br/educacion-es/bordadoen-linea 
GUEDES, M. H. M.; GUeDES, H. M.; ALMEIDA, M. E. F. Efeito da prática de trabalhos manuais sobre a autoimagem de idosos. Rev. bras. geriatr. gerontol., $v$. 14, n. 4, 2011.

LUZ, I. R. P. VIVÊNCIA DA TECELAGEM MANUAL EM UMA TURMA DE 8 ANO DA ESCOLA MUNICIPAL OSÓRIO ALEIXO DA SILVA. $2016.85 p$. (Especialização). Escola de Belas Artes da UFMG Universidade Federal de Minas Gerais, Belo Borizonte MG.

MENDONÇA, M. D.; AGUIAR, S. M. Linhas, Laços e Tramas na Terceira Idade. p. 15p., $2015.2 \quad$ Disponível em: < http://www.cp2.g12.br/blog/propgpec/files/2019/11/Linhas-La\%C3\%A7os-e-Tramasna-Terceira-Idade.pdf >. Acesso em: 21 jan 2021.

PATERNOST, V. A MOTRICIDADE COMO BASE PARA A APRENDIZAGEM: O Estudo de Um Caso pela Reorganização Neurofuncional 2000. 138p. (Mestrado). UNIVERSIDADE ESTADUAL DE CAMPINAS, Campinas SP.

RAMOS, S. P. Políticas e Processos Produtivos do Artesanato Brasileiro como Atrativo de um Turismo Cultura. Revista Rosa dos Ventos v. 5, n. 1, p. 44-59, 2013

SANTOS, D. B. S. D.; SILVA, F. S. D.; CARMO, G. D. Bordadeiras da Namoradinha do Sertão: estudo sobre a produção de bordados da cidade de São João dos Patos VII CONNEPI. Palmas TO 2012.

SETZER, V. W. EFEITOS NEGATIVOS DOS MEIOS ELETRÔNICOS EM CRIANÇAS, ADOLESCENTES E ADULTOS. Sao Paulo, 2014. Disponível em: < https://www.ime.usp.br/ vwsetzer/efeitos-negativos-meios.html >. Acesso em: 21 jan 2021.

RC: 73421

Disponível em: https://www.nucleodoconhecimento.com.br/educacion-es/bordadoen-linea 
SILVA, D. A. A. E. Educação e ludicidade: um diálogo com a Pedagogia Waldorf. Educar em Revista, n. 56, p. 101-113, 2015.

SOUSA, M. D. L. C. M. D. A aplicação da pedagogia Waldorf em alunos com síndrome de DAMP. 2011. 126p. (Mestrado). Universidade Católica Portuguesa, Viseu.

TEIXEIRA, I. A. Bordados em sala de aula. 2018. 45p. (Graduação). Universidade de Brasília, Brasília DF.

TEIXEIRA, J. V. S. A Educação Artística-uma prioridade no sistema educativo português: o contributo das expressões artísticas para o desenvolvimento integral do aluno no 1.․ CEB. 2020. 143 (Mestrado). Instituto Superior De Ciências Educativas Do Douro, Pènafiel.

VERMA, P.; MAHAJAN, S.; KAUR, D. Development of Macrame dresses using textile waste. International Journal of Education \& Management, v. 9, n. 3, p. 130133, 2019.

Enviado: Enero de 2021.

Aprobado: Enero de 2021.

RC: 73421

Disponível em: https://www.nucleodoconhecimento.com.br/educacion-es/bordadoen-linea 